\title{
EL DELITO PRECEDENTE EN EL TIPO DE LEGITIMACIÓN DE CAPITALES (LAVADO DE ACTIVOS)
}

\author{
Frank Mila ${ }^{1 *}$ \\ ${ }^{1}$ Universidad José María Vargas, Profesor Agregado Postgrado, Caracas-Venezuela \\ *Autor para correspondencia: e-mail: frankmila@gmail.com
}

Recibido: 2018/04/02 Aprobado: 2018/05/03

DOI: https://doi.org/10.26621/XIV18.2018.06.A05.PUCESI.2550.6684

\section{RESUMEN}

El desarrollo del presente artículo se circunscribe al estudio desde el punto de vista dogmático del tipo denominado Legitimación de Capitales, paseándose por aproximaciones a las definiciones de sujetos activos y pasivos cualificados según la legislación venezolana, el bien jurídico tutelado, el objeto material, acción típica y los elementos descriptivos y normativos del tipo, haciendo especial referencia a los conceptos "actividad ilícita" y "delito", dada su importancia para la configuración del mismo, así como su relación con el principio de legalidad.

Palabras Clave: Legitimación de Capitales, Delito Precedente, Principio de Legalidad.

\begin{abstract}
The development of this article is circumscribed to the study from the dogmatic point of view of the socalled Legitimation of Capitals, walking through approximations to the definitions of active subjects and qualified liabilities according to Venezuelan legislation, the protected legal good, the material object, typical action and the descriptive and normative elements of the type, making special reference to the concepts "illicit activity" and "crime", given its importance for its configuration, as well as its relation to the principle of legality.
\end{abstract}

Keywords: Legitimation of Capital, Previous Crime, Principle of Legality.

\section{INTRODUCCIÓN}

La presente investigación consiste en un análisis jurídico-penal, según la Teoría General del Delito, del delito precedente en el Tipo de Legitimación de Capitales consagrado en la legislación venezolana. Dicho lo anterior, se estudiará en términos generales su tipicidad objetiva y subjetiva, haciendo especial referencia al elemento normativo "actividad ilícita" para determinar el alcance del delito precedente y su relación con el principio de legalidad, ello en virtud que desde el año 1978, -cuando por primera vez se tipificó en un ordenamiento jurídico el referido delito, específicamente en el artículo 648 del Código Penal italiano (instrumento que se mantuvo vigente hasta el año 1990)-, el mismo que regularmente ha estado asociado a otro tipo principal, lo que quiere decir que este ha estado caracterizado por estar subordinado a otro delito precedente. En este orden resulta menester destacar que en la legislación venezolana no se invoca tal delito precedente, sino que se hace referencia a una "actividad ilícita", sin especificar si se trata de un delito o de cualquier actividad antijurídica. 
En tal sentido, en el derecho venezolano, el tipo principal al cual se asoció en principio, la legitimación de capitales, fue al tráfico de sustancias estupefacientes o psicotrópicas según la Ley Orgánica Sobre Sustancias Estupefacientes y Psicotrópicas (1993). Posteriormente, se tipificó el referido tipo en la Ley Orgánica Contra la Delincuencia Organizada (2005), así como en su correspondiente reforma por la Ley Orgánica contra la Delincuencia Organizada y Financiamiento al Terrorismo (2012), en las cuales se suprimió la exigencia relativa a que los capitales debían provenir de un delito precedente, separándose el carácter exclusivo de su aplicación a delitos asociados al tráfico de drogas, para incluirlo o circunscribirlo a la realización de cualquier "actividad ilícita", siempre que sea cometido en el orden de un grupo estructurado de delincuencia organizada.

Ante tal escenario se hace necesario estudiar el alcance del referido elemento normativo, en el sentido de clarificar si efectivamente la tipificación de la legitimación de capitales abarca a cualquier actividad que sea considerada ilícita (de ser así, se incluirían delitos, faltas y otras conductas fuera de la esfera del derecho penal, siempre que sean consideradas ilícitas), o si por el contrario, a pesar que se haga referencia a "cualquier actividad ilícita", esta debe entenderse como una conducta necesariamente delictiva, en virtud del posible cuestionamiento de la mencionada tipificación y su interferencia con el principio de legalidad penal en su vertiente de la interpretación restrictiva de los tipos penales.

\section{Análisis Dogmático de la Legitimación de Capitales (Lavado de activos)}

La Ley Orgánica contra la Delincuencia Organizada y Financiamiento al Terrorismo (2012) establece la siguiente tipificación:

Legitimación de capitales. Artículo 35. Quien por sí o por interpuesta persona sea propietario o propietaria, poseedor o poseedora de capitales, bienes, fondos, haberes o beneficios, a sabiendas de que provienen directa o indirectamente de una actividad ilícita, será penado o penada con prisión de diez a quince años y multa equivalente al valor del incremento patrimonial ilícitamente obtenido (Ley Orgánica contra la Delincuencia Organizada y Financiamiento al Terrorismo, 2012).

De dicha Ley se estructura el siguiente análisis que incluye los principales elementos para el estudio:

\section{Tipo objetivo}

\section{Sujeto activo}

En un delito, el sujeto activo es quien realiza el tipo. Esto significa, que es quien realiza el verbo de la conducta (autor o partícipe). Se observa así que, en el tipo analizado en principio, se hace referencia a un sujeto activo indeterminado, ya que se emplea la denominación "quien", lo cual se traduce en la ausencia de exigencia de un sujeto activo calificado o cualificado. Sin embargo, a pesar de lo señalado anteriormente, es importante destacar que la Ley Orgánica Contra la Delincuencia Organizada y el Financiamiento al Terrorismo (2012) consagra entre sus definiciones la figura del "grupo delictivo organizado".

En síntesis, según la teoría del delito se trata de un sujeto activo indeterminado y, a la luz de la Ley, a pesar de lo indicado anteriormente, en el marco de la Ley Orgánica Contra la Delincuencia Organizada y el Financiamiento al Terrorismo, el sujeto activo debe tratarse de un grupo estructurado de delincuencia organizada, ante lo cual, nos inclinamos por la primera, ya que se es partidario que el tipo penal debe contener todos -o la mayoría- de los elementos tanto objetivos como subjetivos que permitan su plena interpretación, sin necesidad de recurrir a otras normas, a menos que se trate de remisiones necesarias por razones técnicas o para aplicar normas generales de derecho penal.

\section{Sujeto pasivo}

En relación al sujeto pasivo, se sostiene que es el titular del bien jurídico lesionado por el sujeto activo. Por otra parte, con respecto al sujeto pasivo en el delito analizado, es el "Estado", ya que partiendo de la tesis 
de que se trata de un delito que atenta contra el orden socioeconómico, el titular es evidentemente el Estado agraviado, concretamente los entes u órganos rectores del sistema económico, tal como lo afirma Rebolledo (2007).

\section{Objeto Jurídico (Bien Jurídico)}

Para Roxin (1997), "La misión del Derecho penal como protección de bienes jurídicos es ampliamente reconocida en la doctrina moderna" (p. 70). El mismo autor aduce que:

Llamo bien jurídico a todos los objetos que son legítimamente protegibles por las normas bajo estas condiciones. Estos no son, como muchas veces se supone, sustratos de sentido de naturaleza ideal (si lo fueran no podrían ser lesionados), sino entidades reales: la vida, la integridad física o el poder de disposición sobre valores materiales (la propiedad). Los bienes jurídicos no tienen por qué tener realidad material (Roxin, 1997, p. 450)

Así, la protección de bienes jurídicos se encuentra en concordancia con el principio de mínima intervención del derecho penal, el cual protege valores relevantes para la sociedad. En tal sentido, el bien jurídico es entendido como el interés jurídico protegido por la norma. Ahora bien, en el tipo penal analizado, se trata de un bien jurídico intangible como lo es "el sistema socioeconómico", en virtud que con este tipo de conducta se vulnera el correcto orden y funcionamiento de los sistemas económicos de los países, por lo cual inevitablemente acarrea consecuencias negativas para los mismos, siendo capaz de distorsionar los mercados, la libre competencia, entre otros aspectos. Como corolario, para Rebolledo (2007):

En el delito de legitimación de capitales el bien jurídico tutelado es el orden socioeconómico. El Estado protege el sistema económico y financiero, preservando la estabilidad y licitud de las operaciones o negociaciones financieras, así como incentiva el intercambio de relaciones, y la participación de todos en el proceso económico-social. (p. 31).

En el mismo orden de ideas, Lombardero (2009), indica que: "Así pues, consideramos que el delito de blanqueo de activos es un delito pluriofensivo, que ataca al orden socioeconómico, a la administración de justicia y al bien jurídico protegido por el delito subyacente" (p. 154). Por su parte, Hernández (2008), señala que "Justamente es lo que acontece en el comportamiento en estudio que, indefectiblemente, lesiona, entre otros, la economía nacional, el orden económico social y la administración de justicia” (p. 529). En virtud de todo lo señalado, se puede afirmar que parte de la doctrina nacional y extranjera, insisten en considerar al tipo de legitimación de capitales como un delito pluriofensivo, en virtud que tutela más de un bien jurídico, tales como el orden económico social y la administración de justicia.

\section{Objeto Material}

El objeto material de los tipos penales en general está constituido por la persona o cosa sobre la cual recae directamente la acción típica. En ese sentido, el objeto material del delito de legitimación de capitales está constituido por los bienes procedentes de la actividad ilícita, expresamente: "Capitales", "bienes", "fondos", "haberes" o "beneficios".

\section{Acción Típica}

La acción típica, básicamente se erige como la descripción de un comportamiento humano que puede manifestarse a través de una acción o una omisión relevante para el derecho penal. Por tal razón, tales comportamientos son descritos en los tipos penales. Así, la acción típica en la legitimación está constituida por los diversos verbos rectores establecidos en el artículo 35 de la Ley Orgánica contra la Delincuencia Organizada y Financiamiento al Terrorismo (2012), a saber: "Conversión, transferencia, Traslado, ocultamiento, encubrimiento, simulación, adquisición, posesión, utilización, resguardo, inversión, transformación, custodia o administración" sea de bienes, capitales, haberes o beneficios, con el objeto de ocultar su origen ilícito. 
Sin embargo, autores como Muñoz Conde (2007), opinan que:

... el núcleo de la conducta no recae ahora en la realización de actos de adquisición, conversión o transmisión de los bienes, sino que lo importante es que la realización de estos actos o cualesquiera otros (cualquier otro acto) sea para 'ocultar o encubrir su origen ilícito', o para 'ayudar a la persona que haya participado en la infracción o infracciones a infracciones a eludir las consecuencias legales de sus actos' (p. 538)

Se coincide con el criterio expresado por Muñoz, empero, se considera que se trata más bien de un elemento subjetivo del tipo.

\section{Elementos Descriptivos}

Tal como apunta Jescheck (1981), "Ios elementos descriptivos son aquellos que el juez determina usando las ciencias naturales o sus sentidos. También se considera que son los que el autor puede conocer a través de sus sentidos, susceptibles de una constatación fáctica" (p. 365). En consecuencia, el tipo penal de legitimación de capitales contempla diversos elementos de los denominados descriptivos, los cuales no requieren mayor valoración, ya que como taxativamente lo indican, son meramente descriptivos.

\section{Elementos Normativos}

Los elementos normativos, a diferencia de los elementos descriptivos, no pueden ser conocidos mediante los sentidos, sino que es necesario someterlos a una valoración más profunda. En todo caso, en el tipo penal de legitimación de capitales se precisan diversos elementos normativos, que requieren una interpretación especial, incluso, se erige el denominado "actividad ilícita" que representa uno de los puntos a desarrollar de mayor interés de la presente investigación, siendo analizados en el punto número tres de este estudio.

\section{Tipo Subjetivo}

\section{Tipo Doloso}

La conducta consagrada en el artículo 35 de la Ley Orgánica Contra la Delincuencia Organizada y Financiamiento al Terrorismo, se interpreta que es dolosa, motivado a que en Venezuela rige el sistema "numerus clausus", en el cual se entiende que sólo podrá castigarse la forma culposa siempre y cuando así sea expresamente establecido respecto a cada tipo penal. Sin embargo, debe advertirse que existe una forma culposa de comisión, consagrada en el artículo 36 ejusdem, empero, el tipo penal base que se aborda en la presente investigación es el tipo doloso.

\section{Elementos Subjetivos}

Tal como se apuntó anteriormente, existe un elemento subjetivo que está referido a la realización de cualquiera de los verbos rectores del tipo, con el elemento anímico extra distinto al dolo, de ocultar o encubrir el origen ilícito los bienes de ilícita procedencia. Igualmente, se advierte que no se requiere un ánimo de lucro como elemento subjetivo. Tal como sostiene Lombardero (2009), "Tampoco es preciso el ánimo de lucro como elemento subjetivo del injusto, lo que lo diferencia de la receptación. No es necesario para cometer el delito que se haya objetivo o se pretenda obtener por el autor beneficio alguno" (p. 177).

\section{Elemento normativo "Actividad ilícita" y el principio de legalidad.}

Según el Diccionario Jurídico Elemental de Guillermo Cabanellas (1979), la actividad ilícita, se entiende como: El reprobado o prohibido por el ordenamiento jurídico; el opuesto a una norma legal o a un derecho adquirido. La violación del derecho ajeno. La omisión del propio deber. El daño causado por culpa o dolo en la persona de otro, o en sus bienes y derechos. El contrario a las buenas costumbres y a los principios imperativos de un núcleo organizado. 
Para Ramírez Gronda (1976), los actos ilícitos, se entienden como:

Los actos ilícitos son acciones, pues que tales se consideran aún los de la expresión tácita de la voluntad. Los actos ilícitos pueden ser acciones u omisiones. Acciones, cuando se hace lo que la ley prohíbe; omisiones cuando no se hace lo que la ley manda. Los actos ilícitos sólo se consideran en el derecho, cuando pueden producir alguna adquisición, modificación o extinción de los derechos u obligaciones. En los actos ilícitos no hay distinción que hacer. Como su fin no es fin jurídico, no son ni se llaman actos jurídicos, aunque estén determinadas sus consecuencias jurídicas. El que me roba (...) no se propone ciertamente venir a ser mi deudor, ex delito, para restituir la cosa hurtada e indemnizar todo el daño. Estos son los caracteres diferenciales entre los actos lícitos e ilícitos (p. 34).

Ambas definiciones son genéricas, y lo que se logra deducir de ambas es que se trata de acciones $u$ omisiones, dolosas o culposas, opuestas a una norma legal, que incluso pueden modificar o extinguir derechos, entre las cuales, Cabanellas (1979), incluye los delitos. Como corolario, Moreno Coronel (2011), en relación a lo que se entiende por actividad ilícita, apunta lo siguiente:

Una actividad ilícita primaria generadora de ingresos, capitales, bienes, haberes o beneficios, a los que se procura reinsertar en el "circuito legal", es lo que se denomina como actividad previa, base o determinante, es decir, no depende de un delito previo para su constitución, basta la realización de cualquier acto ilícito o actividad ilícita para que pueda configurarse el delito de legitimación de capitales, una vez se ejecute algún verbo rector. (...) decimos que actividad ilícita es el acto o conducta contraria que prescribe una norma (deber jurídico), es la condición de la sanción. Por tanto, cualquier acto contrario a Derecho, cuando genere capitales, bienes, haberes o beneficios, es decir, susceptible de valor económico (p. 39).

Sostenido lo anterior, se debe dejar claro que, evidentemente un delito y una actividad ilícita son conceptos distintos, a pesar que se pueda afirmar que el delito está incluido en el concepto amplio de ésta última, no obstante, normativamente poseen una estructura distinta, incluso, el delito se maneja con una teoría autónoma gracias a constructos dogmáticos propios. Ahora bien, se debe advertir que no es el objeto de este trabajo dilucidar si un delito puede estar incluido en el concepto de lo que se entiende por actividad ilícita, sino el punto referido a que al hacerse referencia a actividad ilícita, se entiende que el legislador previó la existencia de otras conductas que no necesariamente son constitutivas de delitos, no obstante, son ilícitas, ante lo cual se ve la necesidad de tomar posición al respecto, ya que tal situación incide en el principio de legalidad.

Se debe mencionar que, el principio de legalidad es uno de los pilares fundamentales del Estado Constitucional de Derecho; en ese sentido, tal como apunta Roxin (2007):

...un Estado de Derecho debe proteger al individuo no sólo mediante el Derecho penal, sino también del Derecho penal. Es decir, que el ordenamiento jurídico no sólo ha de disponer de métodos y medios adecuados para la prevención del delito, sino que también ha de imponer límites al empleo de la potestad punitiva, para que el ciudadano no quede desprotegido y a merced de una intervención arbitraria o excesiva del 'Estado Leviatán'. (...) Frente a esto, el principio de legalidad, (...) sirve para evitar una punición arbitraria y no calculable sin ley o basada en una ley imprecisa o retroactiva (p. 137).

\section{Realizando una comparativa con Según el Tribunal Constitucional Español (№ 156 de 14/10/1996):}

El principio de legalidad penal es una garantía inherente al Estado de Derecho, que impone, por razones de seguridad jurídica y de legitimidad democrática de la intervención penal, la estricta sujeción de Jueces y Tribunales al dictado de las leyes que describen delitos e imponen penas y exige la existencia de preceptos jurídicos que permitan predecir con el suficiente grado de certeza 
qué conductas se hallan prohibidas y qué responsabilidad y, en su caso, qué sanción comporta su realización. El efectivo reconocimiento del principio de legalidad penal obliga en ocasiones a dilucidar si se ha traspasado la tantas veces tenue línea divisoria que separa la actividad judicial de reconocimiento del alcance y significado de la norma como paso previo a su aplicación, de la que, con ese mismo fin, rebasa sus límites y genera o modifica su propio sentido.

Visto lo indicado, se debe tomar en cuenta el contenido del principio de legalidad, el cual está conformado por: a) Lex Certa: Ley Cierta (Ley Formal); b) Lex Scripta: Ley Escrita (Prohibición de Costumbre); c) Lex Stricta: Ley Estricta (Prohibición de Analogía); y d) Lex Previa: Ley Previa (Irretroactividad). Siendo afectados por el tipo penal analizado, cada uno de los referidos aparatados antes transcritos, que conforman el aludido principio, ya que la tipificación de la legitimación de capitales al ser plasmada en términos genéricos ante cualquier actividad "ilícita", trastoca cimientos de derecho penal, ya que no se explica la razón por la cual no se castiga penalmente esa denominada actividad "ilícita", pero si los beneficios que se puedan derivar de la misma.

Tal aspecto no se comparte desde la óptica de un derecho penal garantista, el cual pregona la exigencia de leyes claras y precisas, que otorguen seguridad y uniformidad en su aplicación, evitando la discrecionalidad. Por ello, se entiende que una de las funciones del principio de legalidad es la de obtener seguridad jurídica. En tal sentido, la norma penal debe contener todos los presupuestos que condicionan la pena. De esta forma, la ley debe ser clara, hasta el punto que un lego pueda comprender el mandato de prohibición establecido en la norma, a pesar de que existen elementos propios de los tipos penales que requieren la interpretación por parte de un jurista, lo importante es que estén presentes todos los elementos descriptivos, normativos o subjetivos si los hubiere. Aspecto que no se cumple en el tipo penal analizado, ya que supedita la punibilidad al beneficio que pudiera obtenerse por cualquier actividad ilícita, siendo estas ilimitadas, a diferencia de los delitos, los cuales están previamente delimitados, a pesar de contar con un derecho penal colateral-denominación empleada por Carlos Simón Bello (1988)- muy disperso y mayor al derecho penal codificado.

La doctrina no sólo critica que se cuide la redacción de los tipos penales, exigiendo una precisa redacción, sino también el hecho de que no existan tipos penales solapados o el evitar la generalización, abstracción o cláusulas indeterminadas, las cuales no tienen cabida en el ámbito de un derecho penal que rige para los Estados de Derecho.

Erróneamente, sostiene Moreno Coronel (2011), que las conductas ilícitas están perfectamente delimitadas en las leyes respectivas (p. 49). Aspecto que realmente no es así, ya que existe una gran cantidad de conductas ilícitas, que tienen ese carácter gracias a interpretaciones extensivas, que pueden variar según la interpretación que otorgue el juzgador, es decir, son conductas ilícitas que surgen por deducción, no de manera literal o expresa, tal como ocurre con los delitos, que sí están plenamente delimitados, y se interpretan conforme a una dogmática jurídico-penal previamente establecida.

A todas luces, se trata de una interpretación extensiva que está prohibida en materia penal y también, se trata de la configuración de un tipo que castiga únicamente los beneficios de conductas que no necesariamente son punibles. Además, al revisar el Código Penal español, se configura la legitimación de capitales conforme a la comisión de un delito previo, ante lo cual no quedan dudas de la necesidad que los bienes o beneficios que se pretenden legitimar, deben provenir de un delito previo.

Asimismo, internacionalmente esta es la tendencia, así lo establece el artículo 6.1.- del Convenio de Estrasburgo (1990), que se obliga a las partes a penalizar las conductas vinculadas con el avado de las ventajas económicas procedentes de la comisión de delitos, y la Convención de Palermo (2004), en su artículo 6.- establece que se castigue a quienes cometen un delito previo, a partir del cual se obtiene la riqueza a lavar.

Por ello, en teoría, la legitimación de capitales se trata de un delito autónomo, en el sentido, que es independiente del delito previo, a pesar que éste último debe estar presente, es decir, se tipifican las conductas separadas, 
tanto del delito previo como del encubrimiento del mismo (Artículo 24 de la Convención de Mérida). Al igual que se castiga con independencia del lugar donde se cometa el delito previo (artículo 23.2.c ejusdem), y la prioridad de castigar al blanqueador con independencia de su responsabilidad por el delito previo (artículo 23.1.a ejusdem y 6 de la Convención de Palermo).

Por último, se destaca que la jurisprudencia del Tribunal Supremo Español (SSTS de 7-12-96, Caso Necora, entre muchas otras), ha establecido tres elementos que conforman el delito de blanqueo de capitales o legitimación d capitales, a saber:

1.- Incrementos patrimoniales injustificados u operaciones financieras anómalas.

2.- Inexistencia de actividades económicas o comerciales legales.

3.- Vinculación, relación o conexión con actividades de tráfico ilícito de estupefacientes, o con

otras actividades delictivas, o con personas o grupos relacionados con ellas.

De ello se destaca que en relación al último aspecto, se exige que debe tratarse de actividades delictivas y no extenderse a cualquier actividad ilícita. Por tal razón, se considera una exigencia acorde con el principio de legalidad, que el tipo penal analizado deba estar circunscrito a un tipo penal precedente y no a cualquier conducta que abarque cualquier actividad ilícita que no sea punible.

\section{CONCLUSIÓN}

Vistos los señalamientos supra realizados, sirva la presente investigación para advertir la eventual vulneración del principio de legalidad con la tipificación de la legitimación de capitales en la Ley Orgánica Contra la Delincuencia Organizada y Financiamiento al Terrorismo (2012), en referencia a la penalización de beneficios obtenidos por conductas ilícitas que no son constitutivas de delitos, aspecto ilógico, ya que penalmente no es viable castigar beneficios que puedan generarse por cualquier actividad contraria a derecho, sin castigar penalmente la conducta previa per se, tomando en consideración que el derecho propugna una máxima relativa a que lo accesorio sigue la suerte de lo principal.

Por otra parte, se observó que el principio de legalidad propugna la claridad de las normas que conminan su cumplimiento con una sanción penal, ante lo cual no pueden existir dudas, ambigüedades o problemas de interpretación, siendo estas debidamente delimitadas, teniendo presente que existe una gran cantidad de conductas que son consideradas ilícitas y por ello, escapan del derecho penal, ante lo cual, no existe certeza en relación a las normas que pueden generar un castigo penal.

Igualmente, se evidenció que la tendencia mundial a nivel de instrumentos internacionales, así como legislativa, es la de sancionar la legitimación de capitales provenientes de un delito previo o precedente, no ante cualquier actividad ilícita, ya que esto se puede desdibujar y aplicarse un Derecho penal máximo.

Por último, la presente investigación se realizó con la finalidad de servir de base a futuros debates penales relacionados con la referida tipificación y su interferencia con el principio de legalidad penal en su vertiente de interpretación restrictiva, a objeto de considerar de lege ferenda, establecer un catálogo de delitos que delimiten el ámbito de aplicación de la legitimación o en todo caso, plasmar que debe tratarse necesariamente de un delito.

\section{REFERENCIAS BIBLIOGRÁFICAS}

Bello, C. (1988). Ilicitud Penal Colateral. Venezuela y Políticas. Universidad Central de Venezuela.

Cabanellas, G. (1979). Diccionario Jurídico Elemental. Buenos Aires: Heliasta.

Código Penal español (1995). Ley Orgánica 10/1995 de 23 de noviembre de 1995.

Convenio de Estrasburgo (1990). Convenio sobre blanqueo, detección, embargo y confiscación de los productos de un delito. Consejo de Europa.

Convención de Palermo (2004). Convención de las Naciones Unidas Contra la Delincuencia Organizada Transnacional. Naciones Unidas.

Hernández, H. (2008). Los delitos Económicos en la Actividad Financiera 
Jescheck, A. (1981) Tratado de Derecho Penal. España: Editorial Bosch.

Ley Orgánica contra la Delincuencia Organizada y Financiamiento al Terrorismo. Gaceta Oficial N. ${ }^{\circ} 39.912$ de fecha 30 de abril de 2012.

Lombardero, L. (2009). Blanqueo de Capitales. España: Tirant lo Blanch.

Moreno C. (2011). Legitimación de Capitales ¿Delito Transversal?. V Convención contra las Drogas y Legitimación de Capitales. Ministerio Público. República Bolivariana de Venezuela.

Muñoz, F. (2007). Derecho Penal Especial. España: Tirant Lo Blach.

Ramírez, G. (1976). Diccionario Jurídico. Colección Textos Jurídicos Universitarios.

Rebolledo, A. (2007). Legitimación de capitales. Caracas: Vadell Hermanos.

Roxin, C. (1997). Derecho Penal Parte General. Tomo I. Madrid: Editorial Thomson.

Roxin, C. (2007). La Teoría del Bien Jurídico. Madrid: Marcial Pons, Ediciones Jurídicas y Sociales.

Tribunal Constitucional Español, sentencia № 156 de fecha 14 de octubre de 1996.

Tribunal Supremo Español, sentencia Caso Necora de fecha 07 de diciembre de 1996. 